\title{
Examining Elementary Teacher Candidate Learning Within Early Field Experiences in a Partnership
}

\author{
Dr. Kimberly J. Bohannon, Ed.D. \\ Assistant Professor of Elementary Education \\ Keene State College \\ 229 Main St, Keene, NH 03435, USA
}

\begin{abstract}
College and University teacher education programs' partnerships with public schools have been developed to enrich the learning of teacher candidates and support practicing educators. Teacher candidates' development through early field experiences provides insight into the ways the partnership enhances the translation of theory into practice. This article examines teacher candidates' experiences and learning in a unique partnership which engages them in coursework and field experiences within the context of the school each semester. This partnership was created with the intention of providing additional resources to the school to allow for a more student-centered approach to instruction. Teacher candidates are also afforded three additional field placements throughout their preparation program. The experiences between twelve, third year teacher candidates who participated in the partnership between a K-8 elementary school and a liberal arts college teacher education program are examined. Findings indicate that early field experiences within a partnership enhance teacher candidate learning.
\end{abstract}

Keywords: elementary education, field experiences, partnership, site-based experiences, teacher education

\section{Introduction}

Education reform has been in the forefront for policy makers and leaders in the field of education over the past three decades. In a nationwide effort to increase student outcomes, teacher education plays a central role (Grant $\&$ Gillette, 2006). Prior to the 1980s, teacher preparation programs consisted of a sequence of coursework completed on the college campus, followed by a semester-long student teaching experience during which the candidates were able to observe and work within a school setting (Kern, 2004). Reports from the 1980s through the mid-1990s identified the need for reform in education to be led through teacher preparation and outlined avenues for change (National Commission on Excellence in Education, 1983; The Carnegie Foundation on Education and the Economy, 1986; The Holmes Group, 1986, 1990, 1996). Based on the examination of best practices, these reports recommended a new model for teacher preparation, the professional development school (PDS). A recommendation from the Holmes Group (1995) for the institutions of higher education was to form partnerships with teachers and administrators of the cooperating schools (Burton \& Greher, 2007).

The National Center for Education Information's (2011) report states that 94\% of teachers currently in the field have been trained in preparation programs that involve field experiences. The National Council for Accreditation of Teacher Education [NCATE] (2007) states that the purpose of the field experiences is to support teachers in becoming effective classroom teachers. Field experiences provide a contextual framework to enhance the understanding of pedagogical skills and concepts learned in education coursework (Darling-Hammond, 2006; McIntyre, Byrd, \& Foxx, 1996; Posner, 2005). When teacher candidates are able to make these connections, it increases the probability that they will apply these theories, concepts and skills as they begin their teaching careers (Bransford, Darling-Hammond, \& LePage, 2005).

Driving all work in the field of teacher education should be the fact that student achievement is a direct result of effective teaching (Sandoval-Lecero, Shanklin, Sobel, Townsend, Davish, Kalisher, 2011; Stronge, Ward \& Grant, 2011). The No Child Left Behind Act (2002) emphasizes the need for school accountability and highly qualified teachers. With the spotlight on teacher performance in public schools, institutions of higher education have an increased responsibility to focus on the field experiences within their teacher education programs.

Using the recommendations of the previously mentioned national reports, many colleges and universities have therefore arranged partnerships with public schools. 
Teacher candidates who engaged in these partnerships gained increased skills of collaboration, instruction, assessment, and management, and obtained a solid pedagogical foundation (Capraro, Capraro, \& Helfeldt, 2009; Castle, Fox \& Souder, 2006).

\section{Methods}

This study utilizes a qualitative approach to systematically capture the words, actions and experiences of the teacher candidates participating in a partnership (Charmaz, 2006). Qualitative research allows the researcher to take an in-depth look at the candidates' experiences through interviews, lesson plans and observations. The questions considered in this study are: (1) "What are the ways in which teacher candidates demonstrate effective teaching in early field experiences within a partnership?" and (2) "How do the dimensions of a partnership support teacher candidate learning in early field experiences?" The impact of learning in this model is analyzed in order to gain a deeper understanding of the meaning of the early field experiences within the partnership and the connection between theory and practice within a partnership. Content analysis of the data identified patterns, themes and categories to interpret and clearly define the teacher candidates' experiences and the learning that results from these experiences.

\section{Context and Participants}

This study focuses on twelve teacher candidates enrolled as elementary education majors in a small northeastern college in the United States. All candidates were accepted to participate in the partnership cohort at the completion of their first year at the institution. Selection is based on an overall GPA of 2.75 or higher, successful completion of the Praxis Core exam and an interview with the faculty involved in the partnership. Teacher candidates in this study are in their fifth semester of the partnership. The teacher candidates in the partnership cohort are placed in the field three semesters earlier than candidates in the traditional track, experiencing five semester-long field experiences before the full-time student teaching experience.

A small, rural, public school located in northern New England is the school identified in this study. Enrollment at the school is approximately 180 students in kindergarten through eighth grade. The student body is predominately white with less than two percent minorities, which is reflective of the demographic within the state. Approximately fifty percent of students receive free and reduced lunch. Facilitating the learning of these students are 40 full and part time staff, including seventeen regular education classroom teachers, support staff and one principal. Teachers work and plan as teams to provide a child-centered, integrated curriculum.

The K-8 school is engaged in a partnership program with a nearby liberal arts college. This institution of higher education has a population of approximately 5,400 students. An estimated $18 \%$ of the undergraduate students have elected Education as their major. Education faculty consists of eighteen tenure track professors and several adjuncts. The program is accredited by the National Council for Accreditation of Teacher Education (NCATE) and the New England Association of Schools and Colleges (NEASC). The institution works with over twenty schools to deliver hands-on experiences to teacher candidates.

The partnership was created between the two institutions with the intention of providing additional resources to the school to allow a more student-centered approach to instruction with elementary students. At the same time, the college is able to place students in a consistent setting for the duration of elementary teacher candidates' preparation program. College faculty members who are involved attend staff meetings and contribute to school and curricular planning. Along with teacher candidates involved in the partnership, college faculty also often participates in professional development planned for the school staff. It is the responsibility of the college faculty teaching within the partnership program to communicate on a regular basis with the cooperating teachers regarding course content, current instruction, and pedagogy.

After the introductory course, all education classes are taught within the school setting, each with an assigned field experience component. Transportation from the college campus to the school is provided by the college as needed. A cohort model is employed, with no more than fourteen students admitted each year. Teacher candidates experience the same course content as offered in the traditional track, with the exception of an additional course offering in special education and differentiation. Another aspect of the partnership that is different from the experiences of teacher candidates in the traditional track is the access to extensive technology resources at this school. 
All education courses teacher candidates take are held at the K-8 school and include a field experience. Teacher candidates in the partnership program are thereby allowed three additional field placements. uring these field experiences, teacher candidates begin by actively observing the students and teacher and leading routine-based activities. As they continue, they quickly take on teaching responsibilities, first planning and teaching individual lessons, and then progressing to teaching series of lessons and complete units. Due to the relatively small size of the school, teacher candidates from multiple cohorts may be in the classroom at one time. For example, a student in his/her first semester in the partnership may spend two hours in a classroom at the same time as a fifth semester student is in the room; however, the fifth semester candidate remains in the room for a full day. All teacher candidates participate in professional development in co-teaching, along with school staff, to help facilitate this.

\section{Data Collection}

Interviews with teacher candidates in the partnership cohort were conducted to learn the teacher candidates' views of their learning in the partnership model. Interviews with the college instructor and cooperating teachers were conducted to provide the additional perspective of candidates' learning and experiences in early field experiences in the partnership. The interviews conducted in this study help the researcher to develop an understanding of the participants' perspectives on teacher candidate learning within early field experiences in this partnership. To determine the influence of the early field experiences on teacher candidate effectiveness and the impact on their learning, field observations of each teacher candidate served as a second source of data. The researcher, cooperating teachers and college faculty observed each student one time, allowing for three observations of each teacher candidate. Analysis of teacher candidate lesson plans is the third source of data to determine teacher effectiveness. Two lesson plans from each participant were collected. Seven components of the college's consistent lesson plan format were examined.

Danielson's Domains serve as the framework to approach data collection and analysis in this study. Danielson (2007) identified a roadmap of competencies and skills necessary for new teachers to develop. These skills are organized in four domains of teaching: planning and preparation, classroom environment, instruction, and professional responsibilities. Competencies listed under each domain address the knowledge, skills, and dispositions candidates are expected to develop in the program. Danielson's (2007) framework was selected for this study because it is used by the participating college for reflective and evaluative purposes by the Teacher Education department and was recently adopted for use in the evaluation system for elementary school teachers in the partnership school.

\section{Findings}

5.1 Effective Teaching Demonstrated by Teacher Candidates in Early Field Experiences. Teacher candidates engaged in early field experiences within a partnership demonstrate strengths in specific categories of Danielson's (2007) Framework for Effective Teaching. Data collected found evidence of each domain of Danielson's (2007) framework. The components of each domain in which significant evidence was seen in more than half of the teacher candidates, across multiple sources of data, were noted as prevalent.

\subsubsection{Planning and Preparation}

The first domain in the framework, planning and preparation, was the domain in which the most significant evidence was seen across all three sources of data. Planning and preparation includes demonstrating knowledge of students, resources, pedagogy and content, as well as setting instructional outcomes, and designing coherent instruction and assessments (Danielson, 2007). Nine out of twelve teacher candidates indicated planning and preparation as an area of confidence, with none of the candidates indicating a need for further growth in this area. College faculty, Mrs. Smith, noted the candidates' understanding of the importance of content knowledge and child development research in planning, preparing and teaching, "Most significant is the ability of teacher candidates to demonstrate knowledge of students as they understand their students' developmental and learning needs and apply their thinking when teaching lessons in the classroom."Accommodations and modifications were clearly identified in written lesson plans and follow through was evident in most lesson observations. A component of Planning and Preparation that was not seen as often is designing student assessments. While a form of assessment was provided in every lesson plan analyzed and informal measures were observed in the field, these were formative and did not always guide their instruction. In the interviews it was clear that students have been exposed to the ways in which assessments are used, but teacher candidates have not had extensive opportunities to independently design summative assessments.

112 
Due to the teacher candidates' limited roles in the classroom during early field experiences, this would be difficult. Given the extensive amount of time spent in the field, teacher candidates have had multiple opportunities to plan and prepare lessons, as well as to implement these lessons in the elementary classroom. The additional opportunities afforded by early entrance in the field in a consistent placement provide a sense of confidence among candidates and strong skills in planning and preparation.

\subsubsection{Classroom Environment}

The second domain in the framework is Classroom Environment. Danielson (2007) defines effective teaching in this domain as creating an environment of respect and rapport, establishing a culture for learning, managing classroom procedures and student behavior, and organizing physical space. Data related to the domain of Classroom Environment found measureable evidence of the Classroom Environment domain in all candidates, yet fewer candidates demonstrated extensive, significant evidence of this domain. This is often an area that is slower to develop in teacher candidates. Data demonstrates that although the candidates are aware of effective management strategies and most are confident in this area, this does not necessarily translate to their performance in the classroom. Regardless of the success with the strategy employed, students consistently applied management strategies in their teaching and followed through with any redirection given. Another area of this domain that was overwhelmingly present in the data is the area of managing classroom procedures. Teacher candidates recorded strategies in their lesson plans and followed through in their teaching. Candidates also facilitated the engagement of the additional adults in the classrooms. Paraprofessionals, other teacher candidates and the classroom teacher all had responsibilities during each lesson. This could be a result of the co-teaching professional development that this cohort has participated in with the teaching staff at the school. Most evident were the relationships formed with students, as ten out of twelve candidates consistently demonstrate their ability to establish an environment of respect and rapport. The area of this domain that was rarely seen was the component of establishing a culture for learning. This would be difficult to see in isolated field observations or lesson plans, and is a responsibility of the classroom teachers to be followed by the candidates. Looking across the data at this domain, it is clear that this is an area in which many candidates will continue to develop in their culminating field experience.

\subsubsection{Instruction}

Danielson (2007) identifies Instruction as the third domain in the framework. Components of the domain are broad and include communicating with students, using questioning and discussion techniques, engaging students in learning, using assessment in instruction, and demonstrating flexibility and responsiveness. Components of this domain were demonstrated by teacher candidates in this study while still half of the cohort regarded this domain as an area of focus for the future. Christina stated, "Instruction is the area that is always changing, so I will always need to work on this. The content and students change all the time and you have to be on top of that." Reflecting on her work in this domain, Abby said, "I have grown in my presence in the classroom. I still can excel even more at how I present myself in front of the classroom. This will be my focus in student teaching." Despite the teacher candidates' responses, the college faculty and cooperating professionals spoke of strengths in this area. Cooperating teacher, Mrs. Gregory, attributed this to the variety of teaching opportunities they have experienced. Mrs. Smith, college faculty, noted that at least half of the teacher candidates are very comfortable and confident in front of the class and are very skilled in instruction: Expectations for instruction have increased gradually. Students began my observing and talking with individual and assisting with transitions. Lesson planning and teaching quickly moved to small group teaching, to whole group and co-teaching lessons. Some are now preparing and teaching half days.

While measureable evidence was seen in the domain of Instruction, there is less significant evidence of effectiveness in this domain. As noted by cooperating teachers, this is an area in which many teacher candidates, in this partnership and in the traditional track, require extensive practice.

\subsubsection{Professional Responsibilities}

The fourth domain defined by Danielson (2007) is Professional Responsibilities. The wide range of obligations related to a teacher's role include reflecting on teaching, maintaining accurate records, communicating with families, participating in a professional community, growing and developing professionally, and showing professionalism. Teacher candidates in this partnership demonstrated significant evidence of many aspects of this domain. 
The components seen most frequently in all three sources of data were reflecting on teaching, showing professionalism, and participating in a professional community. These aspects of teacher candidates' development have been a focus in all prior coursework. Aspects of this domain that were not seen frequently in the data, such as communicating with parents and maintaining accurate records, do not relate to the role of a teacher candidate in early field experiences. The responsibilities will be added as they progress to student teaching.

Twenty-six of the field observations indicated extensive, significant evidence of Professional Responsibilities and seven out of twelve candidates noted this domain as an area of strength. Given the length of time teacher candidates are in the school setting, they become a part of the professional community. "We became professionally aware of how to interact with students and staff, both inside and outside of the classroom" Madeline stated. The college faculty noted, "Professional responsibilities begin on day one in the first semester." Mrs. Smith cited knowledge, skills and dispositions of confidentiality, professional dress, communication, language, collaboration and ethics across all interviews. Teacher candidates in this partnership also reported feeling a greater sense of professionalism each day they were in the field, regardless of whether it was for a course or time in the classroom.

Kayla remarked: Being unprofessional is not an option. Because we are a part of a school environment each and every day, we know what is expected of us. Parents, administrators, professors and teachers all hold us to high expectations. We learned this very early in the program. Regarding another area of Professional Responsibilities, one cooperating teacher stated: This candidate is able to reflect on a different level that previous students in the traditional track. She is easily able to take her thinking and apply it to the next lesson, as teaching occurs so often. When discussing something that did not work as well as one hoped, these apprentices were then given the opportunity to apply what they had learned. Candidates' abilities to reflect on their teaching in an objective manner were strong. Ten out of twelve candidates provided very accurate reflections of their lessons in their postobservation interviews. One cooperating teacher summarized this domain stating, "The students are a part of our professional community. Many attend data, grade level, staff meetings, and more. They are constantly immersed in professional conversations and therefore I am noticing a high level of professionalism with their interactions."

\subsection{Continual Coursework and Field Experiences Impact Teacher Candidate Learning}

The strongest influence on teacher candidate learning found in this study was the continual coursework and field experiences offered in the context of the school. This model allows for growth in their knowledge, skills, and dispositions. This study is unique in comparison to existing literature, as the coursework and field experiences are described as continual, meaning that all teacher candidates remain in the same partnership school throughout all of their coursework. Additionally, each of these courses has a related field experience component. Eleven out of twelve teacher candidates identified this structure as beneficial to their learning; one was indifferent. All cooperating teachers and faculty also attributed the model of continual coursework and field experiences within the context of the school as being a significant factor in teacher candidate learning. Contextual connections were able to be made during discussions, as students and faculty were all familiar with the school setting, student population and curriculum. For example, when learning about emergent literacy, teacher candidates were able to draw on their experiences in classrooms to identify characteristics of this stage of learning development, as opposed to only reading about it in a text book.

While many teacher education programs offer field experiences at varying points in the program, there is often a gap between the campus courses and the opportunities to observe and employ these practices in the school setting. This is seen both in traditional preparation programs, as well as professional development and partnership schools (Zeichner, 2010). Early field experiences must extend beyond observation and include careful guidance and focus on critical aspects of classroom teaching and student learning (Huling, 1998). Additionally, courses that are connected to field experiences are ineffective if the content is not put into immediate action in the field (Hadfield, Littleton, Steiner \& Woods, 1998).

The results of this study support the connection of theory and practice. The immediacy of this practice for teacher candidates in this partnership is also significant. Within this partnership program, courses are held on site, and time in the field is structured into the class time. In a typical class session early in the program, teacher candidates meet to engage in new learning, disperse to spend time in the field, and then reconvene to make connections and discuss observations. Time spent in the elementary classroom increases as students move through the program. One candidate, Christina, stated, "Nothing is hypothetical; we got to see it right away. 
We completed child studies and learned how to observe objectively." Allison added, "We learned far more by having class in the field. We were able to transfer knowledge from the class into the field, not simulate it." Kathryn said, "It brought the textbooks to life. We would learn about something one minute and see it the next. I would say, "This is what they are talking about." Multiple candidates reported feeling as if the material may not have made as much sense if they were not able to see the content unfolding in the classroom. Faculty also noted this as a significant contribution to candidate learning, as noted in the interviews, "The growth of the candidates has been enhanced by the teaching of the course on site which has immersed the students each day in the reality of the school community." The data in this study supports the connection of theory and practice, but also indicates that the immediacy of this practice is important to teacher candidates' learning.

While many studies conclude that a significant amount of what teachers need to learn must be obtained from practice, the conditions for learning are widely debated (Bransford, Darling-Hammond \& LePage 2005). In this setting, teacher candidates are immersed in the same school setting from the beginning of their second year through their final semester of student teaching. Teacher candidates are integrated in to a field placement every semester. Although their responsibility increases as they progress, they are expected to be fully involved from the beginning. Teacher candidates reported observing and leading routine based activities, such as Morning Meeting, in the first semester, and were then teaching full lessons on the first day of the semester in their second Methods class. Kathryn stated, "In the beginning, our learning was very focused on content. As we grew and were able to understand how to observe and what was going on in the classroom, we were able to focus more on our teaching." Faculty member, Mrs. Smith, noted that after the first three semesters, such confidence and skill is demonstrated that most teacher candidates are able to walk into a classroom readily able to assess student needs and develop ways to meet them.

Across all interviews, it was apparent that the continual connection between the field experience and the course content was important to their learning. Because of the continual coursework and field experience within the context of the same school, candidates were able to see change over time. Mrs. Robinson said, "The biggest advantage to the partnership is the amount of time the college students spend in the classroom. They are able to gain far more experience working with students than the typical program." Another cooperating teacher agreed, stating,

Being placed in a classroom within the same school each semester has provided individual, small and whole group teaching experiences and opportunity for continued growth for candidates. Instruction is planned for so often, candidates easily write lesson plans for multiple lessons each day. Traditional track students prepare far fewer lessons because of the startup time necessary each semester.

Identifying classroom management as her strength, Allison said, "We have seen a variety of different teachers and different grades. We have seen what works and what might not with each group; now we are able to evaluate what will work the best for us and our students." This was also evident in field observations. The language that teacher candidates used often mirrored that of their cooperating teachers. Students were familiar with routines established school-wide, such as the universal attention getting strategy, and employed them during their instruction. Appreciating the contribution to learning from extended amounts of time spent in the school may enhance learning opportunities in teacher preparation programs.

Teacher candidates engaged in partnerships have a greater sense of ownership in the school community (Castle, Fox \& Souder, 2006; Snow-Gerono, 2009). Studies have also noted a heightened feeling of belonging when engaged in a partnership program (Castle, Fox \& Souder, 2006; Sandoval-Lucero, et al., 2010). In this setting, learning is impacted due to the comfort with the learning environment and students grow to develop positive personal and professional dispositions. Seven of the teacher candidates described that the nature of being in the school all the time making them more of a part of the community. "All of the people in the school are invested in our learning," said Christina. Madeline noted the importance of this to their dispositional learning, "We became professionally aware of how to interact with students and staff, both inside and outside of the classroom." Teacher candidates found increased confidence due to their comfort level in this school setting. In over half of the field observations, teacher presence was highly evident in teacher candidates. They were comfortable taking risks and presenting new concepts. This is best supported by the words of Abby: I was not the best student in high school. Being in the partnership and becoming a part of the school community helped to motivate me. My grades went up across all courses. I improved my writing, learned professional ways of working together and it boosted my confidence. 
In traditional teacher education programs, field experiences are viewed as places for teacher candidates to practice teaching, and often teacher candidates lack the support and preparation they need to be successful (Zeichner, 2010). Often cited as a problematic issue in partnerships, communication is a key to ensuring the success of a partnership and teacher candidate growth and success (Ledoux \& McHenry, 2008). Given the structure of this partnership, teacher candidates and faculty are immersed into the school setting. Communication is encouraged among all constituents and occurs on a regular basis. Faculty and cooperating teachers noted that compared to a traditional track, communication between cooperating teachers and teacher candidates is increased in this model, as there is more contact time in the field. Mrs. Smith, the college faculty, stated, "The impact of learning has been most significant by the professional relationships developed over the course of five semesters." Teacher candidates also reported the increased access to their cooperating teachers was beneficial to their learning. Mrs. Gregory, a cooperating teacher spoke of the benefit to their learning, as well:

Having the professors hold classes site-based, they are able to keep stay current with best practices. They are in constant contact with teachers, enabling them to ask questions, clarify their thinking and spend additional time in the classroom. This keeps the information they are presenting to their students relevant.

Teacher candidates and faculty expressed the value of teacher candidates engaging in continual coursework and field experiences as related to teacher candidate learning. This was also demonstrated in the teacher candidates' performance in the classroom during field observations. Understanding the multiple ways in which this model impacts teacher candidate learning may be significant to the field of teacher education as they shape meaningful experiences for teacher candidates.

\subsection{Metacognitive Practices in Early Field Experiences}

Another finding of this study is that engaging teacher candidates in met cognitive teaching practices within a continual site-based experience within a partnership is beneficial to their learning and performance. Metacognitive practices encourage teacher candidates to engage in thinking about their own learning. Danielson (2007) states that in order for teacher candidates to learn from observation of good teaching practice, they must reflect on their practice. Teacher candidate learning is negatively impacted when candidates are not given the opportunity to be involved in the process of examining their own beliefs and experiences in comparison to the practices they see in the field (Capraro, Capraro \& Helfeldt, 2010).Danielson (2007) also argues that teacher educators need to provide the appropriate reflective tools for teacher candidates and they need to be embedded into the curriculum and organization of teacher candidates' education. Aiken and Day (1999) present an opposing view, stating that teacher candidates engaging in early field experiences may not be cognitively ready to benefit from these experiences. They attribute this to their lack of experience and pedagogical knowledge preventing them from appropriately interpreting and analyzing classroom occurrences. The data in this study support the use of reflection, as well as other met cognitive practices.

From early in this partnership program, teacher candidates experience these metacognitive practices, as time is built into the course schedules for reflection and discussion. The college faculty shared, "Daily reflection is essential to candidate learning. This is shared with cooperating teachers and peers." In expressing her feelings about the importance of reflection in her learning, Abby stated: As we reflect as a class on different experiences, we are able to add things we would not have seen in a campus class. This significantly increases our ability to learn and the rate at which it happens. We are also able to share our differing points of view. Whether or not we come to a consensus is not as important as the thought that we all put in.

Allison reported that the amount of reflecting on what teacher candidates had seen or done in the field was as beneficial as reading the texts. Christina further supported this saying, "We know when to be critical of ourselves, but also are comfortable saying what we don't know." A cooperating teacher spoke of Rebecca's ability to grow from engaging in these practices as well: This teacher candidate is able to reflect on a different level than previous students I have worked with who are in the traditional track. She is easily able to take her thinking and apply it to the next lesson, as teaching occurs so often. As a whole, when discussing something that did not work as well as one hoped, these apprentices were then given the opportunity to apply what they had learned. Interviews in this study were conducted immediately or soon after field observations took place. Teacher candidates were asked to discuss the success of their lessons. Mostly, they were able to accurately determine the strengths and weaknesses of their teaching and identify areas for growth and improvement. All college faculty and cooperating teachers, as well as eight teacher candidates identified metacognitive practices as a significant source of learning. 
Reflection, application of theory to the classroom, and the model of being exposed to the material, observing it in the classroom, and then coming back together to discuss this new learning were identified as the primary practices in coursework. The frequency of metacognitive practices in the data demonstrates that teacher candidates in early field experiences within a partnership are able to learn from these experiences.

Cheng, Cheng \& Tang (2010) highlighted that most teacher candidates view teacher education faculty and coursework in higher education as their primary source of ideas and models for teaching. This can produce a narrow viewpoint for teacher candidates and may not always reflect best practices. A drawback to reflection in teacher education courses is that teacher candidates often write what they think faculty members want to hear (Cornish \& Jenkins, 2012). By engaging in the met cognitive practices in early coursework, teacher candidates in this partnership are given the encouragement and guidance to make their own judgments about best practices based on what they have seen and experienced in the classroom and the discussion about the content. Given the nature of the integration of field work and continual discussion in the classroom, teacher candidates in this classroom are continually asked to apply their thinking in their next interaction with students. This requires deeper thought, as follow through in their instruction is necessary. Emily remarked: Learning from each other's experiences is a part of being a cohort. We are able to think about our own teaching, but also to give feedback to others and help them make connections and better their teaching. We are not afraid to challenge one another or even the professors if there is something we disagree with.

Elizabeth remarked, "We do lots of reflecting; it comes as second nature. This has really helped me to think about my teaching because I have to explain it, either in writing or in class to my peers." Adding to this, college faculty, Mrs. Smith, noted, "Some of the best lessons come from students rethinking their instruction in a previous lesson. This is what good teachers do."

The ability to reflect on their teaching was also evident in teacher candidates' lesson plans. Teacher candidates are asked to discuss the planning and instructional aspects of their lessons. Allison noted that, "Writing lesson reflections encourages us to think about our lesson critically, usually before getting feedback from our cooperating teachers or faculty. We are then able to compare it to what they say and think about future lessons." Several students noted changes that they made to their lessons at the last minute due to their knowledge of students and previous instruction in the classroom. For example, Abby said: I was pleased with my decision to modify the lesson at the night before. The students would have struggled with the concepts presented all at once. By breaking the difficult concept down into steps, students seemed to be easily able to follow along. These examples demonstrate the abilities of teacher candidates to effectively reflect on their planning and instruction. These data suggest that considering the importance of applying metacognitive practices to courses connected with early field experiences, may have significance in the field of teacher education.

\section{Discussion}

\subsection{Implications for Teacher Education}

The results of this study emphasize the need to link theory and practice in teacher education. This is demonstrated through teacher candidate learning from the aspects of the partnership that support teacher candidate learning: multiple field experiences within the same school, the delivery of courses in the field with carefully aligned field experience components, extensive feedback from cooperating teachers and college faculty with the same context and the development of reflective practitioners. When teacher candidates are able to make these connections, it increases the probability that they will apply these theories, concepts and skills as they begin their teaching career (Bransford, Darling-Hammond, \& LePage, 2005).

The findings of this study suggest that teacher educators need to extend their thinking beyond simply including field experiences in their program to consider ways in which to assist students in making meaningful connections between content and these experiences. The deliberate connections between the content driven courses that are taught within the elementary school and the field experience components associated with each of these courses strengthens teacher candidate learning.

Teacher candidates note their ability to practice what they are learning, reflect on the experience, and practice again until they reach mastery and are able to demonstrate that they are confident applying what they have learned. Another important consideration for teacher educators is the means by which they assess candidate effectiveness. The Danielson (2007) framework is intended for application by practicing teachers. It is also used to measure areas of effectiveness in teacher candidates in many teacher preparation programs across the nation. 
Some areas that were not evident or were less notable in this study may be related to the teacher candidates' roles and responsibilities in the placement classroom. For example, there was not significant evidence of designing complex assessments in observations or lesson plans; most assessments were formative. Most teacher candidates in early field experiences would not have this responsibility, as lessons often are not sequential due to candidates' limited time in the classroom. Another example of this is seen in the domain of Classroom Environment. Teacher candidates are being evaluated on their ability to manage student behavior, yet in most classrooms, they are following the management techniques established by the classroom teacher. Additionally, while Danielson (2007) clearly defines each of the domains and the components within, there is some room for interpretation. For example, in the component of Classroom Environment, establishing a culture for learning, it is difficult to determine what work has been done by the classroom teacher and how the candidate has contributed, particularly during one isolated lesson. These issues do not indicate a deficit within the partnership model, yet suggest that the framework may not be suited for evaluation of teacher candidates in all areas. Teacher preparation programs must carefully evaluate their measures of assessment, and align their expectations.

\subsection{Multiple Early Field Experiences}

Results of this study support current research on the value of experiencing multiple early field experiences within the context of the same school throughout the course of a preparation program contributes to teacher candidate learning. When cooperating teachers and college faculty work closely with teacher candidates to model, guide and support the practice of course content, learning is increased. In this study, providing teacher candidates with multiple teaching opportunities in a variety of grade levels supported their development. Bridging the gap between theory and practice is difficult when practice teaching is short in duration (Cheng, Cheng \& Tang, 2010). Field experiences that span the course of the semester and are repeated over time allow teacher candidates multiple opportunities to teach, observe and interact with students and professionals within the context of the school.

\subsection{Continual Learning Experiences in the Field}

The transfer of learning of teacher candidates engaged in this partnership is supported by the meaningful and purposefully designed learning experiences. Delivery of content in coursework within this preparation model is intentionally designed to embrace the culture of learning in the partnership school and extends to integrate candidates' experiences in the elementary classrooms. Teacher candidates are given the opportunity to observe veteran teachers, engage in instructional experiences and interact with the same group of children over an extended period of time. Bransford, Brown \& Cocking (2004) note that being in an environment in which learners can see the impact they have on others is motivating.

One aspect of this study that separates it from other research is the nature of the continual coursework and field experiences within the context of the same school. Results of this study suggest that a consistent school setting is a key aspect of developing effective teacher candidates. This provides teacher candidates with the opportunity to observe the same students over a span of time, develop a solid understanding of the school context and to observe multiple teachers over time. Schemas are developed and teacher candidates are able to apply these ideas to their future experiences. The direct contact with students and teachers throughout the duration of the candidate's preparation benefits teacher candidate learning and development.

The physical and social contexts in which a learning experience takes place are a fundamental part of the actual learning that takes place within it (Hutchinson, Moon \& Mayes, 2002). The feelings of belonging and support developed by teacher candidates as a result of being embedded in the culture of the school enable them to take on the professional role of a teacher early in their preparation. Inclusion in professional development, collaboration with teachers and other candidates, interactions with parents, involvement in school decision making and feeling embraced and valued by the staff lead to teacher candidate motivation and learning. As referenced in the findings, all three data sources included evidence of competencies outlined in the domain of Professional Responsibilities. Teacher candidates continually embedded within the same partnership school throughout their program become a part of the professional community, leading to development of professional dispositions. Building relationships between cooperating teachers and teacher candidates as a result of the extended time in the field creates a sense of trust that leads to further growth by teacher candidates. Regularly receiving open feedback from cooperating teachers through daily communication allows teacher candidates to build trust and embrace the feedback they are given. Teacher candidates expressed their desire to serve the school and succeed based on their connections and the relationships they have built. 
Continual communication between the cooperating teacher, college faculty and teacher candidates was found to increase students' abilities to apply the feedback they were given to their work in the classroom. While the lesson plan served as a tool for this communication to be standardized, teacher candidates and cooperating teachers also reported the ability to clarify and enhance communication by the in-person interactions that took place due to frequency of the students being in the school. Teacher candidates were involved in planning meetings, and also engaged in many additional face to face conversations with their cooperating teachers regarding questions around topics such as expectations for lesson development, alignment of standards, and suggestions for change in a drafted lesson plan.

While multiple aspects of the partnership model in this study were found to impact teacher candidate learning, it is unclear whether or not there is a disadvantage to teacher candidate learning as a result of remaining in one school throughout their preparation. Typically, teacher candidates in the traditional track at this institution are exposed to two or three school settings before completion of the program. Additionally, multiple teacher candidates from the different cohorts are often found in one classroom at the same time. While teacher candidates worked well together in all field observations, it is unclear if this impacts the actual amount of independent teaching time each candidate receives. Although the additional teaching experience is beneficial to teacher candidate learning, the teaching opportunities may not always be authentic. It is likely that upon graduation candidates will teach in a classroom with limited or no additional support and this will be very different from their preparation experience.

\subsection{Metacognitive Practices}

The use of met cognitive practices in courses, coupled with the focus on the field experience component of each course, is another aspect of the partnership that impacts the candidates' ability to transfer this knowledge to other contexts. Entering the classroom after being introduced to new learning and seeing evidence of this new concept, and then returning to class to discuss and reinforce the concept is powerful for teacher candidates. When learning experiences are closely monitored by college faculty and cooperating teachers, they are able to provide specific feedback for teacher candidates to consider. Other studies have noted disadvantages when teacher candidates are not given the opportunity to be involved in the interactive process of examining their own beliefs and experiences in comparison to the practices they see in the field (Capraro, Capraro \& Helfeldt, 2010).

\section{Conclusion}

This study examined the impact of early field experiences within a partnership on teacher candidate effectiveness. While the results of this study may only be applicable to this population, the findings are substantial and should be considered by teacher educators. Creating multiple early opportunities for teacher candidates to apply the knowledge, skills and dispositions they have studied to the classroom setting is directly related to their learning. When coursework for teacher candidates is presented within the context of the school, meaningful connections between theory and practice are able to be made by the teacher candidates. This model also allows for greater communication and feedback between the teacher candidate, college faculty and cooperating teacher, which supports teacher candidate learning. The immersion in a supportive professional community supports the development of the candidates' dispositions.

\section{References}

Aiken, I. \& Day, B. (1999). Early field experiences in preservice teacher education: Research and student perspectives. Action in Teacher Education, 21(3), 7-12.

Bransford, J., Brown, A., Cocking, R. (2004). How people learn: Brain, mind, experience andschool. Committee on Developments in the Science of Learning National Research Council: Washington D.C.

Bransford, J., Darling-Hammond, L., \& LePage, P. ( 2005). Introduction. L. Darling-Hammond and J. Bransford (Eds.). Preparing teachers for a changing world: What teachers should learn and be able to do (pp. (1-39). San Francisco: Jossey-Bass.

Burton, S., \& Greher, G. (2007, September 1). School-university partnerships: What do we know and why do they matter?. Arts Education Policy Review, 109(1), 13-24.

Capraro, M., Capraro, R., \& Helfeldt, J. (2010). Do differing types of field experiences make a difference in teacher candidates' perceived level of competence? Teacher Education Quarterly, 37(1), 131-154.

Castle, S., Arends, R., \& Rockwood, K. (2008). Student learning in a professional development school and a control school. Professional Educator, 32(1), 1-15. 
Castle, S., Fox, R., \& Souder, K. (2006, January). Do professional development schools (pdss) make a difference?: A comparative study of PDS and non-PDS teacher candidates. Journal of Teacher Education, 57(1), 65-80.

Charmaz, K. (2006). Constructing grounded theory: a practical guide through qualitative analysis. Los Angeles: SAGE.

Cheng, M. H., Cheng, A. N., \& Tang, S. F. (2010). Closing the gap between the theory and practice of teaching: implications for teacher education programmes in Hong Kong. Journal of Education for Teaching, 36(1), 91-104.

Cornish, L. \& Jenkins, K. (2012). Encouraging teacher development through embedding reflective practice in assessment. Asia Pacific Journal of Teacher Education, 40(2), 159-170.

Danielson, C. (2007). Enhancing professional practice: A framework for teaching. Alexandria, VA: ASCD.

Darling-Hammond, L. (2006). Constructing $21^{\text {st }}$ century teacher education. Journal of Teacher Education, 57(1), 1-15.

Grant, C. and Gillette, M. (2006). A candid talk to teacher educators about effectively preparing teachers who can teach everyone's children. Journal of Teacher Education, 57(3), 292-299.

Hadfield, O., Littleton, C., Steiner, R., Woods, E.. (1998). Predictors of preservice elementary teacher effectiveness in the micro-teaching of mathematics lessons. Journal of Instructional Psychology, 25(1), 34-48.

Helfeldt, J., Capraro, R., Capraro, M., Foster, E., \& Carter, N.. (2009). An urban schools-university partnership that prepares and retains quality teachers for "high need" schools. The Teacher Educator, 44(1), 1-20.

Holmes Group, Inc. (1986). Tomorrow's teacher: A report of the holmes group. East Lansing, MI: The Holmes Group, Inc.

Holmes Group (1995). Tomorrow's Schools of Education. East Lansing, MI: Holmes Group, Inc..

Huling, L. (1998). Early field experiences in teacher education. ERIC Clearinghouse on Teaching and Teacher Education. Washington DC

Kern, S. (2004). Investigation of a student teacher placement model that fosters in-service education in the USA. Journal of In-Service Education, 30(1), 29-56.

Ledoux, M. \& McHenry, N. (2008). Pitfalls of school/university partnerhsips. The Clearinghouse, 81(4), 155160.

McIntyre, D., J., Byrd, D., M., \& Fox, S. (1996). Field and laboratory experiences. In J. Sikula, T. Buttery, \& E. Guyton (Eds.), Handbook of research on teacher education (2nd ed.). New York: Macmillan.

Moon, B., Mayes, A., Hutchinson, S. (2002). Teaching learning and the secondary curriculum in secondary schools. Psychology Press.

National Center for Education Information (2011). Profile of teachers in the U.S. 2011. Washington, D.C.: National Center for Education Information.

National Commission on Excellence in Education (1983). A nation at risk: The imperative for educational reform. Washington, D.C.: National Commission on Excellence in Education.

National Council for Accreditation of Teacher Education. (2001). Handbook for the assessment of professional development schools. Washington, DC: NCATE.

National Council for Accreditation of Teacher Education (2007). NCATE unit standards. Washignton, DC: NCATE.

No Child Left Behind (NCLB) Act of 2001, Pub. L. No. 107-110, § 115, Stat. 1425 (2002).

Parkison, P. (2008). Field placement treatments: A comparative study. The Teacher Educator, 43(1), 29-45.

Posner, G. J. (2005). Field experiences: A guide to reflective teaching (6th ed.). New York: Allyn and Bacon.

Sandoval-Lucero, E., Shanklin, N. L., Sobel, D. M., Townsend, S. S., Davis, A., \& Kalisher, S. (2011). Voices of beginning teachers: Do paths to preparation make a difference?. Education, 132(2), 336-350.

Snow-Gerono, J.. (2009). Voices less silenced: What do veteran teachers value in school-university partnerships and initial teacher preparation?. The Teacher Educator, 44(4), 248-267.

Stronge, J., Ward, T. \& Grant, L. (2011). What makes good teachers good? A cross-case analysis of the connection between teacher effectiveness and student achievement. Journal of Teacher Education, 62(4), 339-355.

Zeichner, K. (2010). Rethinking the connections between campus courses and field experiences in college- and university-based teacher education. Journal of Teacher Education, 61(1/2), 89-99. 